Pacific Journal of Mathematics

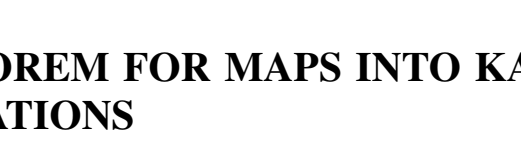




\section{AN APPROXIMATION THEOREM FOR MAPS INTO KAN FIBRATIONS}

\section{RUDOLF FRITSCH}

In this note we prove that a semisimplicial map into the base of a Kan fibration having a continuous lifting to the total space also has a semisimplicial lifiting, very "close" to a given continuous lifting. As a special case we obtain a new proof of the famous Milnor-Lamotke theorem that a Kan set is a strong deformation retract of the singular set of its geometric realization.

First we state our main

THEOREM. Let

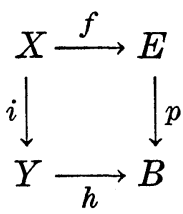

be a commutative square in the category of semisimplicial sets with $i$ an inclusion and $p$ a Kan fibration. Further, suppose given a continuous $\bar{g}:|Y| \rightarrow|E|$ with $\bar{g} \circ|i|=|f|$ and $|p| \circ \bar{g}=|h|$. Then there exists a homotopy $\bar{g} \cong g^{\prime}$ rel. $|X|$ and over $|B|$ so that $g^{\prime}=|g|$ for some semisimplicial $g$.

This theorem has an interesting special case. Take $X=E$ a Kan set, $Y=S|E|, B$ a point, $p, h$ the unique constant maps, $f=i d E, i$ the natural inclusion and $\bar{g}$ the natural retraction. What comes out is the famous Milnor-Lamotke theorem saying $E$ is strong deformation retract of $S|E|$. Thus we get a new proof of this theorem which in contrast to the original one [4] avoids any reference to J.H.C. Whitehead's theorems.

On the other hand, if $B$ is a point, the statement is a trivial consequence of the Milnor-Lamotke theorem. An elementary proof for this case-avoiding the Milnor-Lamotke theorem-has been given by B. J. Sanderson [7] whose techniques are also important for our proceeding.

Proof of theorem. (For the technical details we use the notation explained in $\S 0$ of [1].) By an induction over skeletons, it is enough 
to prove the theorem in the case $y$ is an $n$-simplex $4[n]$ with $n>0$ and $X$ is its boundary $\dot{\Delta}[n]$. Let $c$ be the generating simplex of $\Delta[n], y=h \iota \in B$ and $\bar{y}=S \bar{g}(\iota) \in S|E|$. We have to prove that $\bar{y}$ is $S|B|$-equivalent ([3] p. 123) to a simplex in $E^{1}$.

Decompose $y=y^{+} y^{0}$ with $y^{+}$nondegenerate and $y^{0}$ surjective. We perfom a further induction, over a (partial) ordering of the set of the possible $y^{0}$, that is the set $D_{n}$ of surjective monotone maps with domain $[n]$. Choose ${ }^{2}$ an ordering of this set satisfying (i) and (ii):

(i ) $\beta \alpha \leqq \alpha$ if $\alpha, \beta \alpha \in D_{m}$; and

(ii) each nonconstant $\alpha \in D_{n}$ admits an $\alpha^{\prime}<\alpha$ so that $\alpha^{\prime}$ is the surjective part of $\alpha \sigma_{i} \delta_{j}$ for some suitable pair $i, j$.

Evidently the constant map is the minimum of $D_{n}$ with respect to this ordering.

First, assume $y^{0}$ is constant. Denote by $F$ the fibre over $y$ which is Kan. Now comes Sanderson's idea. Since the boundary of $\bar{y}$ belongs to $F$ we can choose the zeroth vertex * of $\bar{y}$ for base point of $F$. Then, form the path fibration $q: W(F) \rightarrow F([5] \mathrm{p}$. 196) and lift $\bar{y}$ to a filling $\bar{u}$ in $S|W(F)|$ of the horn $\left(-, \bar{y} \delta_{1} \sigma_{0}, \cdots, \bar{y} \delta_{n} \sigma_{0}\right)$ in $W(F) \subset S|W(F)|$. By induction, $\bar{u} \delta_{0}$ is $S|F|$ - equivalent to an $u \in$ $W(F)$. That gives a $\bar{z} \in S|W(F)|$ with boundary $\left(u, \bar{u} \delta_{0}, u \sigma_{0} \delta_{2}, \cdots, u \sigma_{0} \delta_{n}\right)$ and $S|q| \bar{z}=\bar{y} \delta \sigma_{0} \in F$ ([5] p. 25). Next we use that every sphere in $W(F)$ can be filled ([5] p. 196) and also every sphere in $S|W(F)|$ since $W(F)$ is contractible. Take a filling $v \in W(F)$ of the sphere $\left(u, \bar{y} \delta_{1} \sigma_{0}, \cdots, \bar{y} \delta_{n} \sigma_{0}\right)$ and finally a filling $\bar{v} \in S|W(F)|$ of the sphere $\left(\bar{z}, v, \bar{u}, \bar{z} \sigma_{0} \delta_{3}, \cdots, \bar{z} \sigma_{0} \delta_{n+1}\right)$. Then $S|q| \bar{v}$ is an $S|B|$-equivalence between $\bar{y}$ and $q v \in F \subset E$.

If $y^{0}$ is not constant, we choose $i$ and $j$ such that the surjective part of $y^{0} \sigma_{i} \delta_{j}$ is less than $y^{0}$. Set $\varepsilon=0$ if $j<i$ and $\varepsilon=1$ if $j>$ $i+1$. Lift $y$ to $u \in E$ with $u \delta_{k}=\bar{y} \delta_{k}$ if $k \neq j-\varepsilon$ and lift $y \sigma_{i}$ to $\bar{u} \in S|E| \quad$ with $\quad \bar{u} \delta_{i}=\bar{y}, \bar{u} \delta_{i+1}=u, \bar{u} \delta_{k}=\bar{y} \sigma_{i} \delta_{k}$ if $k \neq i, i+1, j . \quad$ By induction, $\bar{u} \delta_{j}$ is $|B|$-equivalent to a $v \in E$ and there is a $\bar{v} \in S|E|$ with boundary $\left(v \sigma_{i+\varepsilon} \delta_{0}, \cdots, v, \bar{u} \delta_{j}, \cdots, v \sigma_{i+\varepsilon} \delta_{n+1}\right)$ and $S|p| \bar{v}=y \sigma_{i} \sigma_{i+1} \delta_{j+\varepsilon}$. Next, lift $y \sigma_{i}$ to $w \in E$ with $w \delta_{i+1}=u, w \delta_{j}=v, w \delta_{k}=\bar{y} \sigma_{i} \delta_{k}$ if $k \neq$ $i, i+1, j$ and lift $y \sigma_{i} \sigma_{i+1}$ to $\bar{w}$ with $\bar{u} \delta_{i+1}=w, \bar{w} \delta_{i+2}=\bar{u}, \bar{w} \delta_{j+\varepsilon}=$ $\bar{v}, \bar{w}_{k}=w \sigma_{i+1} \delta_{k}$ if $k \neq i, i+1, i+2, j+\varepsilon$. Then $\bar{w} \delta_{i}$ is an $S|B|-$ equivalence between $\bar{y}$ and $w \delta_{i} \in E$.

This finishes the proof. As an application, we'll derive a streng-

1 Note that $S|p|$ is also a Kan fibration, by Quillen's result [6].

${ }^{2}$ Cf. the proof of Lemma 4 in [2]. 
thening of this result which is based on the cartesian closedness of the category of semisimplicial sets. Roughly speaking, it states the semisimplicial set of semisimplicial diagonals of a square as in the theorem is a strong deformation retract of the semisimplicial set of its continuous diagonals.

To make this precise, we define the semisimplicial set $D(Y, E)$ of (semisimplicial) diagonals of a square $\left(^{*}\right)$ by means of the following diagram where the sqares involved are pullbacks

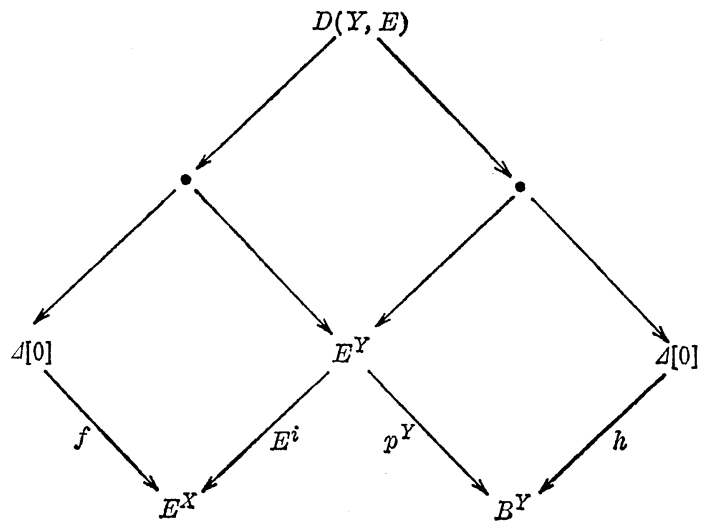

Further, the semisimplicial set of continuous diagonals of $\left(^{*}\right)$ is defined to be the semisimplicial set $D(Y, S|E|)$ of semisimplicial diagonals of the square

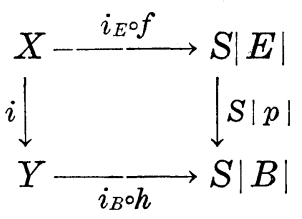

The following lemma gives another description of $D(Y, S|E|)$.

LEMMA. Let

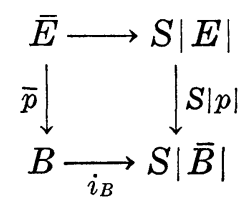

be a pullback. Then the semisimplicial set $D(Y, \bar{E})$ of diagonals of the induced square 


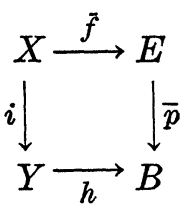

is isomorphic to $D(Y, S|E|)$.

The proof of this lemma is evident. Note the universal property of $\bar{E}$ : The continuous $\bar{g}:|Y| \rightarrow|E|$ so that $|p| \circ \bar{g}$ is realized correspond bijectively to the semisimplicial maps $Y \rightarrow \bar{E}$. If $B$ is a point, this is the adjunction between geometric realization and singular functor.

With these definitions we have the

COROLLARY. Under the assumptions of the theorem on the square $\left(^{*}\right) D(Y, E)$ is an strong deformation retract of $D(Y, \bar{E})$.

Proof. The map $|\bar{E}| \rightarrow|E|$ corresponding to id $\bar{E}$ is a continuous diagonal of the square

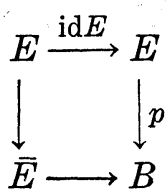

Thus, the theorem implies $E$ is a strong deformation retract of $\bar{E}$. Let $G: \bar{E} \times \Delta[1]$ be a suitable deformation. Further, let $e$ denote the evalution $Y \times \bar{E}^{Y} \rightarrow \bar{E}$ and id $\bar{E}$. Then, by adjointness $G \circ e$ corresponds to a map $K: \bar{E}^{Y} \times \Delta[1] \rightarrow \bar{E}^{Y}$. Its restriction to $D(Y, \bar{E}) \times$ $\triangle[1]$ factors through $D(Y, \bar{E})$ and induces a deformation of the desired kind.

\section{REFERENCES}

1. R. Fritsch, Zur Unterteilung semisimplizialer Mengen, I, Math. Z., 108 (1969), 329-367.

2. - Simpliziale und semisimpliziale Mengen, Bulletin Acad. Polon. Sci., Sér. Sci. Math. Astronom. Phys., 20 (1972), 159-168.

3. P. Gabriel and M. Zisman, Calculus of Fractions and Homotopy Theory, SpringerVerlag, Berlin-Heidelberg-New York, 1967.

4. K. Lamotke, Beiträge zur Homotopietheorie simplizialer Mengen, Bonn. Math. Schr., No. 17 (1963).

5. _ Semisimpliziale algebraische Topologie, Springer-Verlag, Berlin-HeidelbergNew York, 1968.

6. D. G. Quillen, The geometric realization of a Kan fibration is a Serre fibration, Amer. Math. Soc., Proc. AMS, 19 (1968), 1499-1500.

7. B. J. Sanderson, The simplicial extension theorem, Math. Proc. Camb. Phil. Soc., 77 (1975), 497-498. 
Received October 8, 1975 and in revised form March 3, 1976. Research supported by the Universität Konstanz, Forschungsprojekt Nr. 42/74.

FaChbereich MathematiK

UNIVERSITÄT KONSTANZ

Postfach 7733

D-7750 Konstanz 



\section{PACIFIC JOURNAL OF MATHEMATICS}

\section{EDITORS}

RICHARD ARENS (Managing Editor)

University of California

Los Angeles, California 90024

\section{R. A. Beaumont}

University of Washington

Seattle, Washington 98105
J. DugundjI

Department of Mathematics

University of Southern California

Los Angeles, California 90007

D. Gilbarg and J. Milgram

Stanford University

Stanford, California 94305

\section{ASSOCIATE EDITORS}
E. F. BECKENBACH
B. H. NeumanN
F. WOLF
K. YosHIDA

\section{SUPPORTING INSTITUTIONS}

\author{
UNIVERSITY OF BRITISH COLUMBIA \\ CALIFORNIA INSTITUTE OF TECHNOLOGY \\ UNIVERSITY OF CALIFORNIA \\ MONTANA STATE UNIVERSITY \\ UNIVERSITY OF NEVADA \\ NEW MEXICO STATE UNIVERSITY \\ OREGON STATE UNIVERSITY \\ UNIVERSITY OF OREGON \\ OSAKA UNIVERSITY
}

\author{
UNIVERSITY OF SOUTHERN CALIFORNIA \\ STANFORD UNIVERSITY \\ UNIVERSITY OF HAWAII \\ UNIVERSITY OF TOKYO \\ UNIVERSITY OF UTAH \\ WASHINGTON STATE UNIVERSITY \\ UNIVERSITY OF WASHINGTON \\ AMERICAN MATHEMATICAL SOCIETY
}

The Supporting Institutions listed above contribute to the cost of publication of this Journal, but they are not owners or publishers and have no responsibility for its content or policies.

Mathematical papers intended for publication in the Pacific Journal of Mathematics should be in typed form or offset-reproduced, (not dittoed), double spaced with large margins. Please do not use built up fractions in the text of your manuscript. You may however, use them in the displayed equations. Underline Greek letters in red, German in green, and script in blue. The first paragraph or two must be capable of being used separately as a synopsis of the entire paper. Items of the bibliography should not be cited there unless absolutely necessary, in which case they must be identified by author and Journal, rather than by item number. Manuscripts, in triplicate, may be sent to any one of the editors. Please classify according to the scheme of Math. Reviews, Index to Vol. 39. All other communications should be addressed to the managing editor, or Elaine Barth, University of California, Los Angeles, California, 90024.

The Pacific Journal of Mathematics expects the author's institution to pay page charges, and reserves the right to delay publication for nonpayment of charges in case of financial emergency.

100 reprints are provided free for each article, only if page charges have been substantially paid. Additional copies may be obtained at cost in multiples of 50 .

The Pacific Journal of Mathematics is issued monthly as of January 1966. Regular subscription rate: $\$ 72.00$ a year (6 Vols., 12 issues). Special rate: $\$ 36.00$ a year to individual members of supporting institutions.

Subscriptions, orders for back numbers, and changes of address should be sent to Pacific Journal of Mathematics, 103 Highland Boulevard, Berkeley, California, 94708.

PUBLISHED BY PACIFIC JOURNAL OF MATHEMATICS, A NON-PROFIT CORPORATION

Printed at Kokusai Bunken Insatsusha (International Academic Printing Co., Ltd.), 8-8, 3-chome, Takadanobaba, Shinjuku-ku, Tokyo 160, Japan. 


\section{Pacific Journal of Mathematics \\ Vol. 65, No. $2 \quad$ October, 1976}

Andrew Adler, Weak homomorphisms and invariants: an example .......... 293

Howard Anton and William J. Pervin, Separation axioms and metric-like

functions ............................................. 299

Ron C. Blei, Sidon partitions and p-Sidon sets .................... 307

T. J. Cheatham and J. R. Smith, Regular and semisimple modules ........... 315

Charles Edward Cleaver, Packing spheres in Orlicz spaces .............. 325

Le Baron O. Ferguson and Michael D. Rusk, Korovkin sets for an operator on a

space of continuous functions ............................. 337

Rudolf Fritsch, An approximation theorem for maps into Kan fibrations ....... 347

David Sexton Gilliam, Geometry and the Radon-Nikodym theorem in strict

Mackey convergence spaces .................................

William Hery, Maximal ideals in algebras of topological algebra valued

functions ...................................... 365

Alan Hopenwasser, The radical of a reflexive operator algebra ........... 375

Bruno Kramm, A characterization of Riemann algebras................. 393

Peter K. F. Kuhfittig, Fixed points of locally contractive and nonexpansive

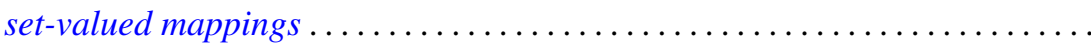

Stephen Allan McGrath, On almost everywhere convergence of Abel means of

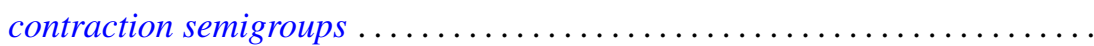

Edward Peter Merkes and Marion Wetzel, A geometric characterization of

indeterminate moment sequences............................ 409

John C. Morgan, II, The absolute Baire property ................... 421

Eli Aaron Passow and John A. Roulier, Negative theorems on generalized convex approximation .................................... 437

Louis Jackson Ratliff, Jr., A theorem on prime divisors of zero and characterizations of unmixed local domains ..............

Ellen Elizabeth Reed, A class of $T_{1}$-compactifications................... 471

Maxwell Alexander Rosenlicht, On Liouville's theory of elementary

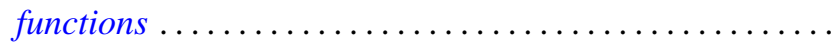

Arthur Argyle Sagle, Power-associative algebras and Riemannian

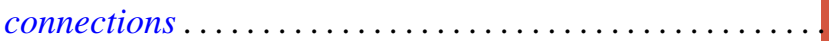

Chester Cornelius Seabury, On extending regular holomorphic maps from Stein manifolds...

Elias Sai Wan Shiu, Commutators and numerical ranges of powers of operators ...................................

Donald Mark Topkis, The structure of sublattices of the product of $n$ lattices ... 525

John Bason Wagoner, Delooping the continuous $K$-theory of a valuation

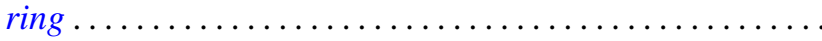

Ronson Joseph Warne, Standard regular semigroups...........

Anthony William Wickstead, The centraliser of $E \otimes_{\lambda} F \ldots$. 